\title{
Evaluating key factors affecting knowledge exchange in social media community
}

\author{
Li-Wen Chuang ${ }^{1}$ and Shu-Ping Chiu $^{2, a}$ \\ ${ }^{1}$ Department of Film and TV Technology, Fuzhou University of International Studies and Trade, China \\ ${ }^{2}$ Department of Fine Art and Design, Fuzhou University of International Studies and Trade, China
}

\begin{abstract}
Today, social media opens up multiple options to add a new channel to learn and obtain knowledge. In particular, social media allows users to learn formal and informal social settings. Users can find like-minded people or community and organize knowledge exchange for educational or other purposes. This paper takes the theory of social network and social capital as the core factors to explore social media community members how to use social media platform to exchange knowledge. The paper uses social network and social capital as predictors of knowledge exchange so that we can use social media as a way to advance knowledge exchange ceaselessly. Therefore, there were 263 members of well-known social media community of knowledge exchange filling out the questionnaires completely, and then evaluated with structural equation modeling, and confirmatory factor analysis was also applied, using SmartPLS 2.0, to test if the empirical data conform to the proposed model. However, results also imply that social capital and social network distinctly play the important part of affecting knowledge exchange and communication about social issues on social media community goes hand in hand with knowledge exchange. Finally, this article proposes implications for theory and practice on the current and future research.
\end{abstract}

\section{Introduction}

Knowledge exchange and knowledge flows all have become an important issue in affecting the development of the social media communities. Because of the mutual communication and collaboration in activities ranging from the economic and marketing to social and educational field, an invisible relationship and other factor have been formed among members about knowledge exchange of social media community. Therefore, the good characteristics of the social media communities can be of some help in understanding where knowledge flows, how knowledge and information is exchanged among members. It can promote the communication and collaboration among members and the formation and development of social media communities. As a result, knowledge exchange is very important issue in the fields of design, information and knowledge management, and considered as a significant research topic by current academic and business circles.

This article is structured as follows: First, the paper discusses the theoretical foundations to review relevant literature and research model related to this study to present the proposed hypotheses along with the research model. Next, the third section, we describe the research methodology and this survey

a Corresponding author : sphill200406@163.com

(C) The Authors, published by EDP Sciences. This is an open access article distributed under the terms of the Creative Commons Attribution License 4.0 (http://creativecommons.org/licenses/by/4.0/). 
data was used to test these hypotheses in this study. Following from the methodology, the empirical results of this article are reported in section 4.

\section{Theoretical foundations and research model}

In section 2, Figure 1 describes the proposed research model. The dependent variable, knowledge exchange, refers to conceptualize a co-production of new knowledge (e.g. information, skills, or ability) through the social interactions of academics and non-academics, individuals and communities(e.g. members, friends, families, groups, organizations), which is of gain or profit to both parties and is explicit from the one way spread of formal and informal research findings[1]. This study, following Wasko and Faraj (2005) [2], contends that social network and social capital are all the critical determinants of knowledge exchange in social media community.

Social media Communities

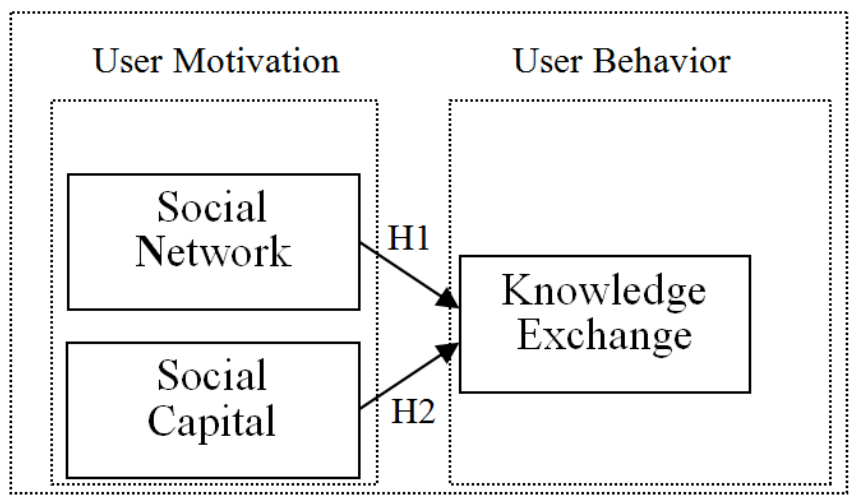

Figure 1. Research Model.

\subsection{Determinants of knowledge exchange}

\subsubsection{Social network and knowledge exchange}

Various knowledge management sources (such as members, friends, families, communities, organizations, customers, common interest groups and government agencies) are valuable for users to control knowledge and information in effect. Individuals can easily obtain unique knowledge through interactions and socials with members within or outside of their social media communities. Even more influential than knowledge/information knows where this knowledge/information is located and how it can be applied. Therefore, to exchange, acquire and share necessary knowledge and information, persistent effort must be made to interact formally and informally and to connect with members and join social networks associated with proper knowledge databases to promote the performance of social media community [3]. And then, some studies have shown that social and human networks are important channels for exchanging, acquiring, transferring and sharing knowledge [2, 4, 5, 6, 7]. Accordingly, following hypothesis is proposed in this study:

H1 Social network is positively related to knowledge exchange.

\subsubsection{Social capital and knowledge exchange}

Following Chiu et al.(2006)[9], social capital is the network of relationships had by an individual or a social network and the set of resources embedded within it, strongly affect the extent to which interpersonal knowledge exchange and knowledge sharing occurs. Thus, another study also argues that individuals' behavior is a product of their social network. Through close social capital, members 
are able to increase the depth, breadth, and efficiency of mutual knowledge exchange [9]. Therefore, Wasko and Faraj (2005) also indicated that the significant levels of social capital and knowledge exchange will develop and contribute knowledge exchange to others in electronic networks of practice [2]. Therefore, the next hypothesis predicts the following:

$\mathrm{H} 2$ - Social capital is positively related to knowledge exchange.

\section{3 research methodology}

\subsection{Measurement development}

The measurement items of our research in the instrument were adapted from the literature. For all the measures, a five-point Likert scale was used with anchors ranging from strongly disagree (1) to strongly agree (5). Items for knowledge exchange were adapted from Yang et al. (2009) [10]. Social identity was measured with items adapted from Chiu et al. (2006) [9]. Social network was measured with items adapted from Bruque et al. (2008) [11].

\subsection{Data analysis and results}

The proposed model was tested using data collected from members of famous social media community, one of the largest and widely social media communities of knowledge exchange and to have observed a solid rise in its adoption and use within the last 2 to 6 years in the real world. By the time this survey was concluded, 263 complete and usable questionnaires had been collected for data analysis.

We analyzed the proposed model in this research, based on the standpoints of Ahuja and Thatcher (2005) and Hair et al. (2010) [12,13]. This study used Structural Equation Modeling (SEM) with Partial Least Squares (PLS) skill to analyze our proposed hypotheses, applied the following procedures. First, by using SmartPLS, the research carried out reliability and validity tests were performed to validate the measurement model. Next, we tested the structural relationships among latent constructs. Data analyses in detail for both the measurement and structural models were performed by using PLS. The remaining of the section describes the investigation procedures.

\subsection{Reliability and validity tests}

The research model using SmartPLS version 2.0 M3 from Ringle et al. (2005) [14], this research individually assessed the proposed model for the full sample and each factor to assure the reliability and validity.

Table 1. Descriptive statistics

\begin{tabular}{cccccc}
\hline Constuct & Item & $\begin{array}{c}\text { Factor } \\
\text { loading }\end{array}$ & $\begin{array}{c}\text { Cronbach's } \\
\boldsymbol{\alpha}\end{array}$ & $\begin{array}{c}\text { Composite } \\
\text { reliability }\end{array}$ & AVE \\
\hline \multirow{2}{*}{ Social } & $\mathrm{SC1}$ & 0.91 & & & \\
Capital & $\mathrm{SC2}$ & 0.90 & 0.84 & 0.91 & 0.76 \\
& $\mathrm{SC} 3$ & 0.81 & & & \\
Social & $\mathrm{SN} 1$ & 0.96 & & & 0.90 \\
Network & $\mathrm{SN} 2$ & 0.96 & 0.95 & 0.97 & \\
& $\mathrm{SN} 3$ & 0.93 & & & \\
Knowledge & $\mathrm{KE} 1$ & 0.93 & & & 0.89 \\
Exchange & $\mathrm{KE} 2$ & 0.95 & 0.94 & 0.96 &
\end{tabular}


As for reliability, most scholars use 0.7 as the recommended threshold for reliable dimensions [15, 16]. As shown in Table 1, all composite reliabilities and Cronbach's $\alpha$ of the constructs had a value greater than 0.7 , expressing the acceptable reliability of the constructs.

As for validity, following Fornell and Larcker (1981) and Anderson and Gerbing (1988) [16, 17], convergent validity is verified when all factor loadings are significant and exceed 0.6, construct reliabilities exceed 0.8 , and average variance extracted (AVE) by each construct should exceed the variance due to measurement error for that construct (i.e. AVE should exceed 0.50). For the full sample, all factor loadings were above the 0.7 threshold (see Table 1), the composite reliabilities of the constructs ranged between 0.97 and 0.91 and AVE ranged from 0.76 to 0.90 (see Table 1). Moreover, discriminant validity is concerned, if the square root of AVE of each construct is larger than its correlations with the other construct, discriminant validity is proved [16]. Table 2 shows all the diagonal values exceed the interconstruct correlations coefficient for the full sample. Therefore, this sample indicates an adequate validity value.

Table 2. Discriminant validity

\begin{tabular}{ccc}
\hline Construct & KE & SN \\
\hline KE & 094 & SC \\
SN & 0.74 & 094 \\
SC & 0.76 & 0.820 .87 \\
\hline notes: & 1.Diagonal:Square Root of AVEs reported along \\
& diagonal in bold. \\
& Off-diagonals: Correlation between latent variables . \\
& 2. KE: Knowledge Exchange; \\
& SN: Social Network; \\
& SC: Social Capital.
\end{tabular}

\subsection{Hypothesis testing}

To examine the statistical significance of the parameter estimates, the research implemented bootstrapping procedure with replacement using 500 subsamples $[8,15]$. A summary of these results is presented in Fig 2. As shown in Fig 2, the variables explain considerable proportions of the variance- $62 \%$ for knowledge exchange. As expected, Social network had the significant effect on knowledge exchange $(\beta=0.343, \mathrm{t}=4.129)$, thus supporting hypothesis H1. Social capital was positively associated with knowledge exchange $(\beta=0.481 ; \mathrm{t}=6.179)$, supporting hypotheses $\mathrm{H} 2$.

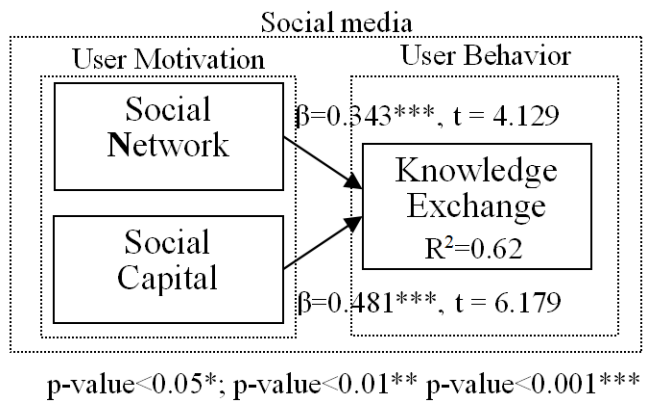

Figure 2. Model Analysis Results

\section{Discussion and conclusion}

The research indicates a proposed model including distinct kinds of knowledge exchange motivations (social network and social capital). This research model demonstrates that for an individual who is dominated by the source of motivation, users can be motivated by the proposed motivation. We, 
however, do not suppose that users can not be motivated by other motivations. According to Chiu et al. (2006) indicated that individual can be characterized by motivational profiles which reflect the relative strength of each of the sources and every individual is dominant by a source of motivation [9]. This implies that people can be motivated by a second source of motivation if the dominated one is absence. This research model supports results of hypotheses H1 and H2 proposed in the research. Investigation of the results shows social network and social capital all have positive and significant influence on knowledge exchange. The unique finding agrees with scholars' viewpoints. Furthermore, it is illustrated that social network and social capital are the key motivation for knowledge exchange of social media community. After the motivation is satisfied by communication and interaction on social network and social capital, user's later knowledge exchange behavior will happen with more efficiency.

To the end, two practice implications can also be applied. Firstly, why it is important to understand the main motivation of knowledge exchange? Because knowledge exchange is not a human natural instinct of exchange/sharing. Knowledge exchange will make members loss value and benefits brought by unique knowledge in community. Actually, in social media community, all members take pleasure from knowledge exchange. The root reason deserves further study. Utilizing social network and social capital, this study finds relevant users may actively choose a social media community due to their demands on communication and interaction. After users' demands are met, their subsequent use behaviors will be influenced. Such finding conforms to scholars' viewpoints. Moreover, it is demonstrated that social network and social capital are the main motivation for knowledge exchange of social media community. After the motivation is satisfied by communication and interaction on social network and social capital, user's subsequent knowledge exchange behavior will happen with equal efficiency. Secondly, when knowledge published by a member is trusted by other members or members all have positive interactions in knowledge exchange and communication in social media community, members will be more willing to exchange knowledge, and quality of knowledge and desire of continuous knowledge exchange behavior will be enhanced.

\section{References}

1. C. Fremantle, M.N. Gulari, S.M. Fairburn, L.A. Hepburn, G. Valentine and L. Meagher, Proceedings of the 20th DMI: Academic Design Management Conference (DMI:ADMC) (2016)

2. M.M. Wasko and S. Faraj, MIS Quarterly, 29(1), 35-57 (2005)

3. H.S. Lee, S.H. Lee and J.T. Han, International Journal of Digital Content Technology and its Applications, 7(12), 307-312 (2013)

4. G. Lei and G. Xin, Journal of System and Management Sciences, 1(3), 79-89 (2011)

5. J.A. Baum, T. Calabrese and B.S. Silverman, Strategic Management Journal, 21, 267-294 (2000)

6. J.H. Dyer and K. Nobeoka, Strategic Management Journal, 21, 345-367 (2000)

7. M.L. Wasko, S. Faraj and R. Teigland, Journal of the Association for Information Systems, $\mathbf{5}$ (11):2, 493-513 (2004)

8. A. Majchrzak, C.M. Beath, R.A. Lim and W.W. Chin, MIS Quarterly, 29(4), 653-672 (2005)

9. C.M. Chiu, M.H. Hsu and E.T. Wang, Decision Support Systems, 42(3), 1872-1888 (2006)

10. H.L. Yang and C.Y. Lai, Behaviour \& Information Technology, 30(1), 131-142 (2009)

11. S. Bruque, J. Moyano and J. Eisenberg, Journal of Management Information Systems, 25(3), 177 206 (2008)

12. M.K. Ahuja and J.B. Thatcher, MIS Quarterly, 29(3), 427-459 (2005)

13. J.F. Hair, W.C. Black, B.J. Babin, R.E. Anderson and R.L. Tatham, Multivariate Data Analysis (NJ, America, 2010)

14. C.M. Ringle, S. Wende and A. Will, SmartPLS 2.0.M3 (2005).

15. W.W. Chin, Modern methods for business research - The partial least squares approach for structural equation modeling (NJ, America, 1998)

16. C. Fornell and D.F. Larcker, Journal of Marketing Research, 18, 39-50 (1981)

17. J.C. Anderson and D.W. Gerbing, Psychological Bulletin, 103, 411 (1988) 